\title{
KAJIAN TEORITIS : TUJUAN KURIKULUM PADA MATA PELAJARAN BAHASA ARAB
}

Abdul Ghofur, Aidah Novianti Putri, Farichatul Ula Safarina Farda IAIN Surakarta ghofurjantran68@gmail.com, aidahnoviaputri@gmail.com ichafarichaa@gmail.com

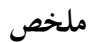

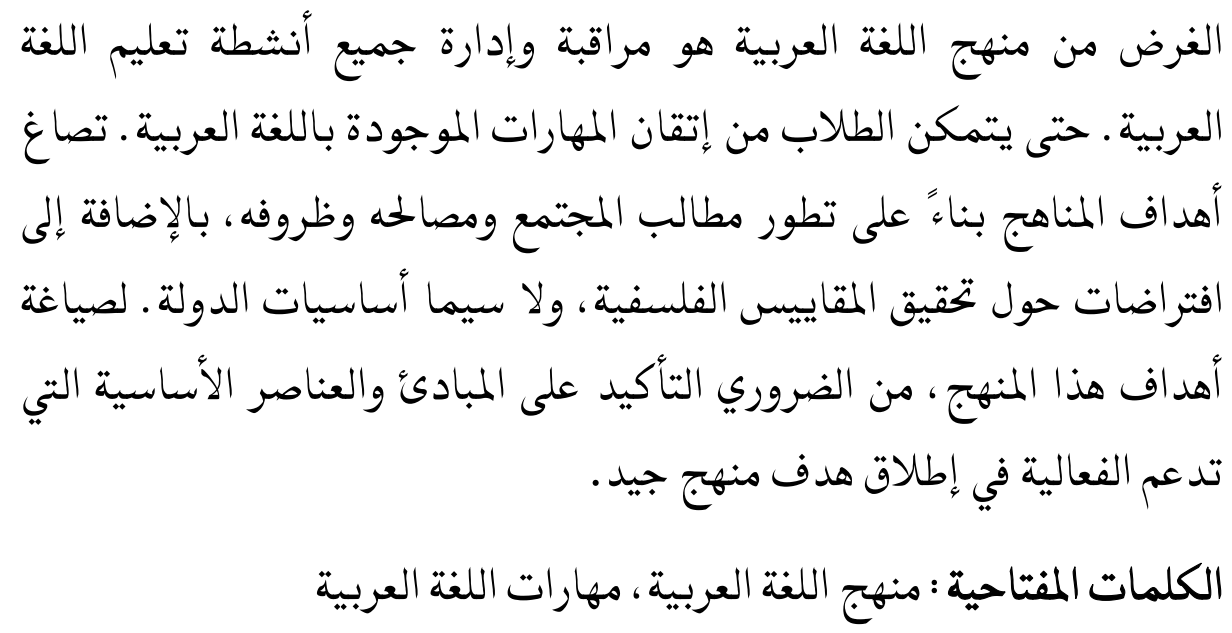

Abstract

The purpose of the Arabic language curriculum is to monitor and manage all Arabic learning activities. So that students can master the skills that exist in Arabic. Curriculum objectives are formulated based on the development of claims, interests and conditions of society, in addition to assumptions on the achievement of philosophical scales, especially the fundamentals of the state. To formulate the objectives of this curriculum, it is necessary to emphasize the basic principles and elements supporting effectiveness in triggering a good curriculum object.

Keywords: Arabic Language Curriculum, Arabic Language Skills 
Abdul Ghofur, Aidah Novianti Putri, Farichatul Ula Safarina Farda : Kajian Teoritis :

Tujuan Kurikulum Pada Mata Pelajaran Bahasa Arab

\section{Pendahuluan}

Kurikulum merupakan sebuah komponen penting dunia pendidikan yang terkadang seringkali diabaikan oleh para tenaga pendidik. Adanya kurikulum untuk memonitoring seluruh kerangka kegiatan edukasi akan mewujudkan tujuan edukasi. Selain itu, kurikulum juga menjadi objek operasionalisasi pembelajaran dalam proses pendidikan. Karenanya tujuan pendidikan tidak akan berhasil tanpa adanya kurikulum pendidikan yang dijalankan. Sebagai suatu disiplin ilmu, perkembangan kurikulum saat ini sangatlah signifikan, menurut teori atau ptaktik. Kurikulum dirancang, diuraikan dan dimajukan untuk dapat memperoleh tujuan edukasi, yakni mencetak generasi yang dapat hidup bersosialisasi di masyarakat. Selain memuat sasaran dan pedoman edukasi, kurikulum merupakan kemahiran menuntut ilmu dan perlu dikuasai oleh siswa dan dengan seperti apa peserta didik tersebut dapat mengaktualisasikannya. ${ }^{6}$

Seiring berjalannya waktu, terjadinya perubahan kurikulum pun seolah menjadi topik pembicaraan penting dalam dunia pendidikan. Berkembangnya kurikulum di Indonesia sudah melintasi begitu banyak peningkatan serta modifikasi. Perubahan serta pembaharuan kurikulum terjadi dikala tahun 2004, 2006 dan 2013. Kurikulum 2004 terfokus atas esensi yang dialihkan menjadi kurikulum berbasis kompetensi. Setelah itu di tahun 2006 berlaku

6 Wina Sanjaya. Kurikulum dan Pembelajaran (Jakarta: Kencana, 2008), hlm. 10

\section{IHTIMAM}


Abdul Ghofur, Aidah Novianti Putri, Farichatul Ula Safarina Farda : Kajian Teoritis : Tujuan Kurikulum Pada Mata Pelajaran Bahasa Arab

modifikasi kurikulum yang dirancang melalui tingkat satuan pendidikan. Dan di tahun 2013 beralih sebagai kurikulum yang diorientasikan guna menyusun dan meningkatkan personalitas siswa atau yang biasa disebut dengan K-13.

Kurikulum harus bersifat aktif. Dengan begitu para pengembang dan pembaharu perlu mempunyai pengetahuan yang ensiklopedis dan mendetail tentang kurikulum. Penilaian dilakukan secara bertahap pada kurikulum yang dijalankan sebagai upaya untuk merekonstruksi dan penuntasan kurikulum. Setiap rekonstruksi dan penyempurnaan kurikulum tidak selalu menjadikan entitas, materi dan objek tersebut lebih baik sebab kurikulum menyimpan perangai spekulasi atau dugaan. Lantaran berhasil dan tidaknya sebuah implementasi kurikulum dapat terlihat pada objek di lapangan. Untuk itu perbaikan dan pengevaluasian kurikulum sangatlah krusial dan signifikan. ${ }^{7}$

Sebagai salah satu bahasa asing menjadikan bahasa Arab seringkali digunakan pada fraksi universal. Untuk itu bahasa Arab begitu signifikan untuk diajarkan, dibudidayakan serta dikembangkan di Indonesia. Perkembangan bahasa Arab pun diperkirakan pada mula kedatangan Islam di Indonesia yakni pada abad ke-13 Hijiriyah. Perancangan kurikulum edukasi bahasa Arab pada tahun 2004 hingga kurikulum 2013 berbasis ancangan yang

7 Zainal Arifin, Konsep dan Model ..., hlm. 2 
Abdul Ghofur, Aidah Novianti Putri, Farichatul Ula Safarina Farda : Kajian Teoritis : Tujuan Kurikulum Pada Mata Pelajaran Bahasa Arab

mudah dipahami. ${ }^{8}$ Proses pembelajaran bahasa Arab di Madrasah Tsanawiyah maupun Madrasah Aliyah secara operasional, baik dari aspek mekanisme, esensi serta penentuan tujuan pembelajaran masih mengalami tendensi terhadap ancangan skema yang memprioritaskan dimensi ilmu bahasa ketimbang peranan bahasa. Sehingga secara global kurikulum yang telah diimplementasikan dan dikembangkan belum dapat di orientasikan dengan baik selain dengan pelaksana dan pelaku edukasi.

Tiap kurikulum yang sempat di implementasikan menyimpan elemen tersendiri yang mengisi ide beserta asumsi logis di masanya yang bertujuan untuk membentuk siswa yang selaras dengan intensi edukasi di masa itu. Asumsi yang terkandung butuh ditelaah lebih mendalam guna dapat menanggapi dan merespon berbagai konflik paradigma kurikulum yang seringkali mengalami modifikasi pada tiap masanya.

Terjadinya modifikasi dan perkembangan kurikulum mengharuskan seorang tenaga pendidik dapat memahami dan mengaplikasikan segala bentuk edukasi dengan baik. Namun hal itulah yang saat ini menjadi problematika beberapa tenaga pendidik dalam melakukan operasionalisasi pembelajaran pada peserta didiknya. Sistematika pembelajaran yang diterapkan di beberapa sekolah atau madrasah masih terlepas dari paradigma

${ }^{8}$ Indah Kumalasari, Perkembangan Kurikulum Bahasa Arab di Pendidikan Bahasa Arab (PBA) Fakultas Ilmu Tarbiyah dan Keguruan UIN Sunan Kalijaga Yogyakarta, Tesis Program Pasca Sarjana UIN Sunan Kalijaga Yogyakarta. 2015. hlm. 222. 
Abdul Ghofur, Aidah Novianti Putri, Farichatul Ula Safarina Farda : Kajian Teoritis : Tujuan Kurikulum Pada Mata Pelajaran Bahasa Arab

tujuan kurikulum yang ada. Dan juga banyak sekali mata pelajaran yang dalam penerapannya masih belum selaras dengan dirumuskannya intensi kurikulum. Oleh karena itu, perlu adanya keselarasan antara guru, murid dan implementasi tujuan kurikulum, agar intensi edukasi bisa diperoleh sebagaimana mestinya.

\section{Tujuan Kurikulum}

Kurikulum adalah rancangan pengajaran tentang program edukasi suatu sekolah atau madrasah sekaligus sebagai program kemahiran belajar siswa pada institusi edukasi. Berdasarkan Ensiklopedia Pendidikan kurikulum merupakan uraian perencanaan dan perangkat yang digunakan insitut pendidikan sebagai suatu cara untuk dapat melahirkan tujuan pendidikan. ${ }^{9}$ Pada pengertian lain juga dijelaskan, bahwasanya kurikulum merupakan seperangkat kegiatan, fasilitas, serta program sebuah lembaga pendidikan dalam upaya menjadikan nyata visi serta misi dari lembaganya. Sedangkan dalam kamus Tarbiyah, kurikulum pendidikan (منهج الدراسة) adalah serangkaian media dan perencanaan sebagai patokan oleh institusi pendidikan dalam merealisasikan arah intensi edukasi. Maka dari itu, kurikulum memiliki kedudukan yang strategis dan berpusat dalam setiap proses pendidikan.

9 Syamsul Bahri, "Pengembangan Kurikulum Dasar dan Tujuannya", Jurnal Ilmiah Islam Tutura, Vol.XI No.1, Agustus 2011, hlm. 17 
Abdul Ghofur, Aidah Novianti Putri, Farichatul Ula Safarina Farda : Kajian Teoritis :

Tujuan Kurikulum Pada Mata Pelajaran Bahasa Arab

Tujuan memiliki peranan sangat penting dalam sebuah kurikulum dan pembelajaran, karena adanya tujuan dapat mengatur dan membimbing seluruh kegiatan suatu pembelajaran. Perkembangan kebutuhan, tuntutan dan kondisi masyarakat serta pemikiran-pemikiran pencapaian dalam nilai-nilai filosofis, terutama falsafah negara, maka dirumuskan tujuan kurikulum. ${ }^{10}$

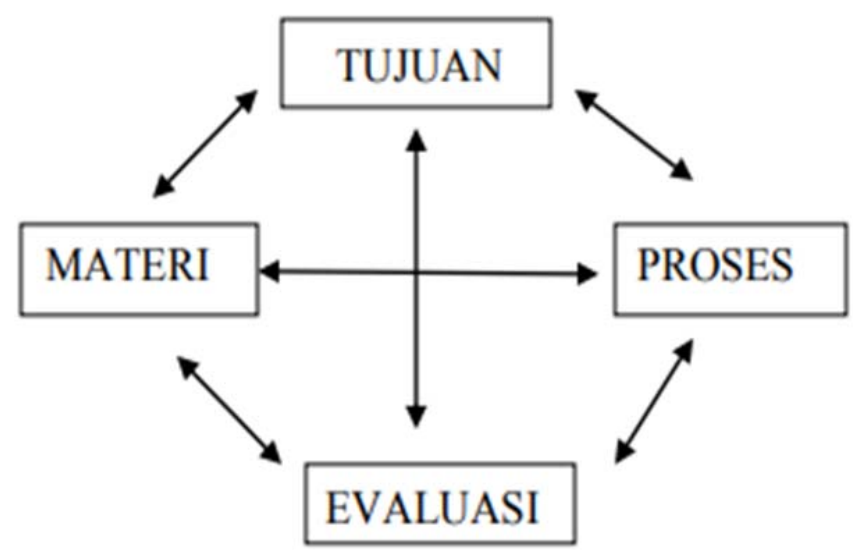

Tujuan pendidikan dapat diperoleh melalui kurikulum, hingga butuh pemaparan berangkat dari intensi global dalam praktik edukasi nasional. Tujuan kurikulum perlu dirincikan dari tujuan umum pendidikan dalam tatanan pendidikan nasional lantaran merupakan isntrumen guna meraih intensi pendidikan. Tujuan umum pendidikan pada dasarnya membentuk pola manusia yang dapat hidup mandiri pada aspek aktivitas individu,

10Sholeh Hidayat, "Pengembangan Kurikulum Baru", (Bandung: PT Remaja Rosdakarya, 2017), hlm. 51 
Abdul Ghofur, Aidah Novianti Putri, Farichatul Ula Safarina Farda : Kajian Teoritis : Tujuan Kurikulum Pada Mata Pelajaran Bahasa Arab

kekerabatan, berkelompok, dan berumat sebagai insan Tuhan. Oleh sebab itu, tujuan pendidikan menjadi orientasi sekaligus target puncak yang patut diperoleh pada program bimbingan dan didikan.

\section{Paradigma Tujuan Kurikulum pada Pembelajaran Bahasa Arab}

Kurikulum Berbasis Kompetensi, Kurikulum Tingkat Satuan Pendidikan dan Kurikulum 2013 merupakan beberapa jenis kurikulum yang sempat dijalankan dalam program edukasi di bangsa ini, berlandaskan rumusan bahwa pengkajian bahasa Arab bertujuan untuk dapat menguasai bahasa Arab itu sendiri dari berbagai aspeknya. Bidang ilmu bahasa Arab dan lintas minat keagamaan berintensi untuk meningkatkan kemahiran korespondensi dalam berbahasa secara tersirat maupun tersurat, menstimulasi dan menanamkan pemahaman tentang urgensi bahasa Arab, menguraikan pemahaman signifikansi berbahasa serta memajukan wawasan adat.

\section{Perumusan Tujuan Kurikulum pada Kemahiran Berbahasa}

Istilah tujuan dalam bahasa Arab disebut dengan الهذف dan الغرض. Tujuan pembelajaran merupakan seperangkat hasil pembelajaran yang mencakup peserta didik, peserta didik, yang meliputi wawasan, kecakapan dan ketrampilan serta tingkah laku yang bersangkutan sehingga dapat mencapainya setelah terjadinya proses pembelajaran. Oleh karena itu, adanya tujuan kurikulum 
Abdul Ghofur, Aidah Novianti Putri, Farichatul Ula Safarina Farda : Kajian Teoritis :

Tujuan Kurikulum Pada Mata Pelajaran Bahasa Arab

bahasa Arab tak lain untuk dapat mewujudkan pembelajaran maharah-maharah yang ada ada dalam bahasa Arab. ${ }^{11}$

1. Tujuan Umum:

Menguatkan materi pembelajaran bahasa Arab dalam empat bidang maharah berbahasa, yang merangkum, mendengarkan (استماع)), berbicara (كلام), membaca (قرأة) dan menulis (كتابة).

2. Tujuan khusus:

a. Meraih tahap keahlian berbahasa yang meliputi fungsional, epistemic performatif dan informational. Pada tahap fungsional, diharapkan peserta didik cakap berbahasa Arab dalam menjalankan keperluan hidup sehari-hari misalnya qiro'ah al-jaridah. Pada tahap epistemic, peserta didik diharapkan bisa mengekspresikan pengetahuannya ke dalam perkataan target. Lalu pada tahap performatif, diharapkan peserta diidik cakap dalam membaca, menulis, mendengarkan dan berbicara memakai simbol-simbol yang ada. Sedangkan pada tahap informational, peserta didik diharapkan bisa mengakses ilmu dengan kecakapan berbahasa.

b. Membentuk peserta didik yang mahir berbahasa yang meliputi kecakapan berbicara (مهارة كلام), menyimak (مهارة

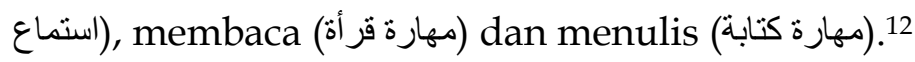

11 Munir, "Perencanaan Sistem Pengajaran Bahasa Arab", (Jakarta: Kencana, 2016) hlm. 88

\section{IHTIMAM}


Abdul Ghofur, Aidah Novianti Putri, Farichatul Ula Safarina Farda : Kajian Teoritis : Tujuan Kurikulum Pada Mata Pelajaran Bahasa Arab

Tujuan kurikukum yang dirumuskan memuat fungsi tertentu dalam rancangan sistematika pembelajaran yang akan dijalankan, diantaranya menjadi tolak ukur pengkajian, mendesain pola belajar peserta didik, syarat untuk mendesain substansi edukasi serta sarana informatif dan komunikatif para tenaga pendidik. Asas-asas signifikan pada perumusan tujuan pembelajaran diantaranya adalah: tujuan pembelajaran harus berjenjang, mencakup berbagai aspek, termasuk sarana untuk merancang mode pengkajian.

\section{Penjenjangan Tujuan Kurikulum Bahasa Arab}

Penjenjangan intensi edukasi bahasa Arab dapat dilihat dari beberapa pandangan, diantaranya ; penjenjangan berdasarkan waktu pencapaian tujuan, tingkat/kelas pembelajaran, dan logika keilmuan. Dilihat dari aspek waktu, tujuan pembelajaran bahasa Arab dapat dikategorikan sebagai tujuan jangka panjang, antara dan pendek. Tujuan jangka panjang pengkajian bahasa Arab yaitu dengan semua peserta didik memiliki keterampilan bahasa Arab serta mampu menjadikannya sebagai profesi (المهنة) dan keterampilan (المهارات الحياوية). Tujuan jangka menengah disebut juga tujuan antara, yaitu tujuan pembelajaran bahasa arab pada tingkat atau waktu tertentu dari sebuah proses pembelajaran yang panjang. Sedangkan tujuan jangka pendek dari pembelajaran bahasa arab

12 Achmad Muhlis, "Pengembangan Kurikulum Bahasa Arab", (Okara, Vol. I, Tahun 9, Mei 2014), hlm.114 
Abdul Ghofur, Aidah Novianti Putri, Farichatul Ula Safarina Farda : Kajian Teoritis :

Tujuan Kurikulum Pada Mata Pelajaran Bahasa Arab

adalah yang berhubungan dengan waktu proses pembelajaran berlangsung, dan biasanya meliputi aspek yang sempit.

Tingkat tujuan pembelajaran berkaitan erat dengan jenjang institusi atau lembaga tempat prosedur pembelajaran berjalan. Perencanaan pembelajaran ini mencakup tujuan secara institusional, kurikuler, dan instruksional. Tujuan Kurikuler pelajaran bahasa Arab merupakan suatu perencanaan yang ingin dicapai dari bidang studi tertentu, yang merupakan pecahan dari bahasa Arab dan pada uni pendidikan tertentu, seperti halnya pengajaran (قواعد) di Fakultas Tarbiyah berbeda dengan pengajaran (قواعد) di Fakultas Syari'ah.

Tujuan intruksional bahasa Arab merupakan tujuan pembelajaran pada setiap pertemuan pembelajaran atau pada saat waktu kegiatan belajar mengajar. Tujuan edukasi ini merupakan penjelasan dari tujuan kurikuler dan dirumuskan berdasarkan tema dan subtema yang disesuaikan dengan waktu yang telah tersedia. Penjenjangan tujuan pembelajaran bahasa arab berdasarkan logika keilmuan merupakan analisis dalam memahami tingkat kesulitan materi-materi ilmu pengetahuan.

\section{Perspektif Intensi Pengkajian Bahasa Arab}

Ditinjau dari dimensinya, rancangan intensi edukasi bahasa Arab berlandaskan atas klasifikasi ilmu dan komponen-komponen bahasa Arab. Intensi edukasi bahasa Arab terbagi atas intensi intelektual, tingkah laku serta keterampilan (skill). Tujuan

\section{8}


Abdul Ghofur, Aidah Novianti Putri, Farichatul Ula Safarina Farda : Kajian Teoritis : Tujuan Kurikulum Pada Mata Pelajaran Bahasa Arab

intelektual yakni menelaah wawasan abstrak nan ideal yang berkaitan dengan bahasa Arab. Keahlian menerapkan dan mempraktikkan ide-ide, persepsi serta konsepsi bahasa Arab dalam manifestasi bahasa disebut intensi tingkah laku atau watak. Sedangkan lahirnya kepekaan dan sensibiltas atas setiap fenomena atau indikasi bahasa Arab merupakan uraian dari intensi keterampilan atau skill.

\section{Tujuan Kurikulum dalam Pengajaran Maharah Bahasa Arab}

1. Tujuan Pembelajaran Maharah Istima (Mendengar)

Tujuan pembelajaran pada maharah ini dikelompokkan menjadi tujuan umum dan khusus. Terdapat tujuan jangka panjang dan pendek yang termasuk tujuan universal/umum yang tak lain supaya siswa bisa mencerna setiap ucapan bahasa dan menginterpretasikan idiom berbahasa baik di dalam maupun luar ruang belajar. ${ }^{13}$ Secara umum, tujuan pembelajaran maharah istima' diantaranya adalah :

a. Mengembangkan kecakapan mendengarkan dan juga peka terhadap pelajaran yang didengarkan

b. Mengembangkan kecakapan menerima dan merespon pesan suara dari pelajaran yang di dengarnya

c. Latihan untuk menangkap suara di tengah-tengah sebuah percakapan dengan sigap dan cermat.

13 Munir, "Perencanaan Sistem Pengajaran Bahasa Arab", (Jakarta: Kencana, 2016) hlm. 39 
Abdul Ghofur, Aidah Novianti Putri, Farichatul Ula Safarina Farda : Kajian Teoritis :

Tujuan Kurikulum Pada Mata Pelajaran Bahasa Arab

d. Mengembangkan cara berpikir dengan cekatan sehingga sanggup mengkaji bunyi yang didengarnya. ${ }^{14}$

Adapun tujuan khusus dari pembelajaran maharah istima' diantaranya adalah:

a. Memafhumi dengan baik teknik tata bunyi, intonasi, tanda bunyi, aksen bunyi huruf sambung \& pisah yang didengarnya.

b. Memafhumi secara efektif makna kosa kata, fungsi istilah kata ataupun kalimat

c. Mengerti tradisi asing, terkhusus tradisi Arab. ${ }^{15}$

\section{Tujuan Pembelajaran Maharah Kalam (Berbicara)}

Pembelajaran kalam dikelompokkan menjadi kalam dialog serta kalam monolog (المحادثة) (التعبير الثفهي). Secara global, pelajaran kalam bertujuan supaya siswa memiliki kecekatan membentuk kalimat sempurna yang sesuai gramatika bahasa Arab, menentukan istilah-istilah yang cermat dan sesuai kerangka teks, dapat berasumsi serta berbicara fasih menggunakan bahasa Arab. ${ }^{16}$ Adapun tujuan umum pembelajaran maharah kalam yang lain adalah, memahirkan siswa untuk melafalkan ungkapan secara jelas dan fashih, berpikir dan berbicara menggunakan bahasa Arab dan dapat

\footnotetext{
14 Ibid, hlm.146

${ }^{15} \mathrm{Ibid}, \mathrm{hlm} .40$

16 Ibid, hlm. 40-41
} 
Abdul Ghofur, Aidah Novianti Putri, Farichatul Ula Safarina Farda : Kajian Teoritis : Tujuan Kurikulum Pada Mata Pelajaran Bahasa Arab

menggunakan ungkapan kalimat yang selaras dengan makna dan gramatika bahasa Arab. ${ }^{17}$

\section{Tujuan Pembelajaran Maharah Qiroah (Membaca)}

Terdapat dua jenis pembelajaran qiroah, diantaranya adalah (القرأة الصامتة) / Qiroah Shamitah atau membaca dengan batin, dan (القرأة الجهرية) / Qiroah Jahriyah atau membaca bersuara untuk seni bacaan. Secara konvensional, target dari pengajaran maharah qiroah yaitu agar siswa dapat membaca setiap teks Arab dengan benar, serta dapat menangkap keutuhan arti yang tersimpan dari teks wacana. ${ }^{18}$

Tujuan umum pembelajaran maharah qiroah yang lain diantaranya, peserta didik dapat membaca dengan fashih, menafsirkan dan mennaggapi istilah-istilah kontekstual dan ragam pikiran dalam tulisan, makna dasar dan meluaskan ide, menganalisis kelebihan dan kekurangan sebuah pernyataan, mengkritik isi bacaan serta mencermati hubungan antara makna dengan lafadh.

\section{Tujuan Pembelajaran Maharah Kitabah (Menulis)}

Kitabah dalam arti menulis apa yang didengar disebut imla' (الإملاء), sedangkan kitabah dalam arti menulis ide, gagasan atau pikiran seseorang disebut insya' (الإنشاء) atau ta'bir tahriri

\footnotetext{
17 Ibid, hlm. 160

18 Ibid, hlm. 41
} 
Abdul Ghofur, Aidah Novianti Putri, Farichatul Ula Safarina Farda : Kajian Teoritis :

Tujuan Kurikulum Pada Mata Pelajaran Bahasa Arab

19 Objek pelajaran kitabah yakni supaya siswa dapat menyimpan kemahiran untuk menulis setiap ucapan yang ditangkap serta dapat memanifestasikan persepsi dalam bentuk karangan yang sesuai dengan ragam sintaksis bahasa Arab. ${ }^{20}$

Adapun tujuan umum dari pembelajaran maharah kitabah adalah :

a. Memafhumi unsur tulisan pada huruf Arab, paham pada perubahan suatu tulisan yang berhuruf Arab \& karakteristik harakatn serta tanda bacanya.

b. Dapat menulis kata per-kata yang pernah dilihat dan didengar dengan sistematis

c. Cakap untuk menulis kalimat yang mendeskripsikan pendapat yang ada di pikirannya

d. Menciptakan semangat, motivasi serta minat peserta didik dalam menulis

\section{Komponen-komponen Pengaruh Penerapan Kurikulum}

Pada penerapan sebuah kurikulum, terdapat beberapa faktor pengaruh, diantaranya :

a. Individualitas kurikulum, meliputi ruang lingkup konsep aktual suatu kurikulum bagi objek di lapangan.

b. Strategi penerapan, sebagaimana diskusi seminar, penyuluhan, sanggar kerja, pengadaan buku kurikulum, serta

19 Ibid, hlm 183-184

${ }^{20} \mathrm{Ibid}, \mathrm{hlm} 42$ 
Abdul Ghofur, Aidah Novianti Putri, Farichatul Ula Safarina Farda : Kajian Teoritis : Tujuan Kurikulum Pada Mata Pelajaran Bahasa Arab

aktivitas yang dapat aktivitas yang mampu memacu pelaksanaan kurikulum tersebut.

c. Karakteristk/partikularitas objek kurikulum, melingkupi pemahaman, kecekatan, dan perilaku tenaga pendidik pada kurikulum, dan kinerjanya dalam mewujudkan kurikulum dalam proses belajar mengajar. ${ }^{21}$

Faktor-faktor yang dapat mendukung keberhasilan penerapan kurikulum diantaranya:

a. Keselarasan kompetensi pengajar dan tenaga kependidikan berdasarkan buku teks juga kurikulum

b. Ketersediaan bacaan sebagai sarana untuk belajar

c. Konsolidasi tugas pemerintah dalam pengamatan serta bimbingannya

d. Pemantapan manajemen sekolah serta tradisi yang ada. ${ }^{22}$

Hal-hal lain yang dapat menunjang keberhasilan dari pelaksanaan kurikulum di sebuah lembaga diantaranya adalah, adanya tenaga pendidik yang berdedikasi tinggi, fasilitas dan dana yang penuh, produktifnya manajemen kurikulum, terjaganya adat yang agamis, bermoral, kewarganegaraan, pemimpin yang idealis, jelas dan bertanggungjawab. ${ }^{23}$ Faktorfaktor yang dapat menghambat keberhasilan dari implementasi

21 Sholeh Hidayat, "Pengembangan Kurikulum Baru", (Bandung: PT Remaja Rosdakarya, 2017). hlm.158

22 Ibid, hlm.156

23 Syamsul Bahri, "Pengembangan Kurikulum Dasar dan Tujuannya", Jurnal Ilmiah Islam Tutura, Vol.XI No.1, Agustus 2011, hlm. 18 
Abdul Ghofur, Aidah Novianti Putri, Farichatul Ula Safarina Farda : Kajian Teoritis :

Tujuan Kurikulum Pada Mata Pelajaran Bahasa Arab

kurikulum diantaranya adalah, adanya pendidik atau guru yang minimnya keterlibatan dan keikutsertaan dalam peningkatan kurikulum, perbedaan asumsi dari kalangan guru atau kepala sekolah dan tata usaha, keahlian serta pemahaman pendidik yang kurang berkompeten dalam mengarahkan peserta didiknya.

Perihal dan perkara yang harus ditekankan seorang penyelenggara pendidikan saat membimbing, mendidik sekaligus mengarahkan mutu-mutu edukasi perlu mengenal, memafhumi dan menangkap taraf-taraf dalam kekerabatan, berasas kerakyatan, berasusila, moralitis dan bermartabat, serta menghormati dan bermaslahat pada corak adatnya seorang diri. Penerapan kurikulum akan berambang pada aktualisasi edukasi, yakni dengan jalan apa substansi dari standar kompetensi kurikulum dapat dikuasai oleh peserta didik secara cermat dan ideal. Dalam hal ini, tugas pokok seorang tenaga pendidik ialah mengkualifikasikan dan menfasilitasi area belajar siswa agar dapat membantu berlakunya perbaikan dari tindakan tersebut. Oleh Karena itu, perlu adanya keselarasan antara tenaga pendidik, murid, dan kurikulum yang berlaku pada lembaga tersebut. 
Abdul Ghofur, Aidah Novianti Putri, Farichatul Ula Safarina Farda : Kajian Teoritis : Tujuan Kurikulum Pada Mata Pelajaran Bahasa Arab

\section{Kesimpulan}

Adanya tujuan kurikulum bahasa Arab ditujukan untuk dapat memonitoring dan mengatur segala aktivitas pembelajaran, dimana siswa dapat menguasai keterampilan-keterampilan yang ada dalam bahasa Arab. Tujuan kurikulum dirumuskan berdasarkan perkembangan gugatan, hajat dan keadaan masyarakat juga asumsi-asumsi pada pencapaian skala-skala filosofis, terutama fundamen negara. Dalam merumuskan tujuan, kita juga perlu menekankan prinsip-prinsip dasar serta elemnelemen penunjang keefektifan dalam mencetuskan objek kurikulum yang baik. Perlu adanya keselarasan pada aspek tujuan kurikulum yang berlaku, seperti halnya adanya komponenkomponen pendukung yang dapat merealisasikan implementasi kurikulum yang sedang dijalankan, diantaranya individualitas kurikulum, skema penerapan serta partikularitas objek kurikulum. Elemen-elemen lain yang mendukung keberhasilan penerapan kurikulum diantaranya, tenaga pendidik yang berdedikasi tinggi, produktifnya manajemen kurikulum, terjaganya adat yang agamis dan bermoral, serta adanya pemimpin yang idealis, jelas dan bertanggung jawab. 
Abdul Ghofur, Aidah Novianti Putri, Farichatul Ula Safarina Farda : Kajian Teoritis :

Tujuan Kurikulum Pada Mata Pelajaran Bahasa Arab

\section{Daftar Pustaka}

Abdulloh, 2010, Pengembangan Kurikulum Teori dan Praktek, Yogyakarta: Ar Ruzz Media

Achmad Muhlis, 2014, Pengembangan Kurikulum Bahasa Arab, OKARA (1): 114

Ahmad Mukhlasin, Rakhmat Wibowo, 2018, Desain Pengembangan Kurikulum Integratif dan Implementasi dalam Pembelajaran. Jurnal Tawadhu Vol. 2 no.1

Asmariani, 2014, Prinsip-Prinsip Pengembangan Kurikulum Dalam Perspektif Islam. Jurnal AL-AFKAR, Vol. III, No. II

Azkia Muharom, 2015. Jurnal Pendidikan Bahasa Arab dan Kebahasaaraban, Vol.2, No. 2

Famahato Lase, 2015, Dasar Pengembangan Kurikulum Menjadi Pengalaman Belajar. Jurnal PG-PAUD STKIP Pahlawan Tuanku Tambusai, Volume 1, No. 2

Hamalik, Oemar, 2011, Dasar-Dasar Pengembangan Kurikulum. Bandung: PT Remaja Rosdakarya

Aksara

Hidayat Sholeh, 2017, Pengembangan Kurikulum Baru, Bandung: PT Remaja Rosdakarya

Karima Nabila Fajri, Proses Pengembangan Kurikulum, Jurnal Keislaman dan Ilmu Pendidikan, Volume 1, Nomor 2 
Abdul Ghofur, Aidah Novianti Putri, Farichatul Ula Safarina Farda : Kajian Teoritis : Tujuan Kurikulum Pada Mata Pelajaran Bahasa Arab

Muhbib Abdul Wahab, 2008, Epistemologi dan Metodologi Pembelajaran Bahasa Arab, Jakarta: Lembaga Penelitian UIN Jakarta

Muhzin Nawawi, 2017, Pengembangan Kurikulum Pendidikan Bahasa Arab. An-Nâbighoh, Volume 19 No. 1

Nuryani, 2015. Implementasi Kurikulum Pendidikan Bahasa Arab. TA'ALLUM, Vol. 03, No. 02

Munir. 2016. Perencanaan Sistem Pengajaran Bahasa Arab, Jakarta: Kencana

Sankholid Nasution, 2016, Pengembangan Kurikulum Bahasa Arab. Bahasa dan Seni. 44.(2):143

Sukmadinata, Nana Syaodih, 2009, Pengembangan Kurikulum : Teori dan Praktek. Bandung: PT Remaja Rosdakarya

Syaifuddin Sabda, 2011.Pengembangan Kurikulum. Yogyakarta: Aswaja Pressindo

Syamsul Bahri. 2011. Pengembangan Kurikulum Dasar dan Tujuannya. Jurnal Ilmiah Islam Tutura. 9 (1) :18 Roviin, 2018. Jurnal Tarling Vol. 1 No. 2

Tim Pengembang MKDP,2012.Kurikulum dan Pembelajaran.Jakarta:PT Grafindo Persada

Walfajri, 2018. Landasan Pengembangan Kurikulum Bahasa Arab. AnNabighoh. Vol. 20, No. 01

Wina Sanjaya, 2008. Kurikulum dan Pembelajaran, Jakarta: Kencana 
Abdul Ghofur, Aidah Novianti Putri, Farichatul Ula Safarina Farda : Kajian Teoritis :

Tujuan Kurikulum Pada Mata Pelajaran Bahasa Arab

Widodo Winarso. 2015. Dasar Pengembangan Kurikulum Sekolah. Cirebon: Universitas Atma Jaya

Yoce Aliah Darma, Sri Astuti, 2017. Landasan Ilmu Pendidikan. Bandung:Rafa Production

Zainal Arifin. 2011. Konsep dan Model Pengembangan Kurikulum. Bandung: PT Remaja Rosda Karya 